\title{
How unusual was autumn 2006 in Europe?
}

Geert Jan van Oldenborgh

Royal Netherlands Meteorological Institute, De Bilt, Netherlands; oldenbor@knmi.n

Meteorologically, the autumn of 2006 was an extraordinary season in Europe (van Oldenborgh, 2007). In the Netherlands, the 2-meter temperature at De Bilt averaged over September-November was $1.6^{\circ} \mathrm{C}$ higher than the previous record since regular observations began in the Netherlands in 1706, which was a tie between 1731 and 2005 (Fig. 1a). Figure 1b shows that the area with $3^{\circ} \mathrm{C}$ anomalies stretches from the Alps to Denmark and from Belgium to Poland. This made it by far the warmest autumn on record in the UK, Belgium, the Netherlands, Denmark, Germany and Switzerland. Pre-instrumental reconstructions indicate that SeptemberNovember 2006 was very likely the warmest autumn since 1500 in a large part of Europe (Luterbacher et al., 2007).

The impacts of the high temperatures on society and nature were not very strong because a higher temperature in autumn corresponds to a phase lag of the seasonal cycle. However, a similar anomaly in summer would have given rise to a heat wave analogous to the summer of 2003, which caused severe problems (e.g., Schär and Jendritzky, 2004).

\section{Return times}

Figure 1a shows that the autumn temperature at De Bilt for 2006 is well above the values observed previously. How rare the event was can be quantified by computing its return time. A return time of 100 years means that the probability of the event happening is $1 \%$ every year. As the autumn 2006 temperature is unprecedented, the return time is computed by extrapolation of a fit to the other observations. In autumn, a normal distribution fits the data quite well. The position of the 2006 temperature in the tail of this distribution then gives the return time.

First, we compute the return time of autumn 2006 in the Netherlands under the assumption that there are no long-term climate variations, only interannual variability. This gives a return time of 10,000 years. The high value implies that the assumption is false: climate does change on longer timescales. Global warming has made high temperature anomalies much more likely in the last decades, and this decreases the return times of recent high extremes.

a)

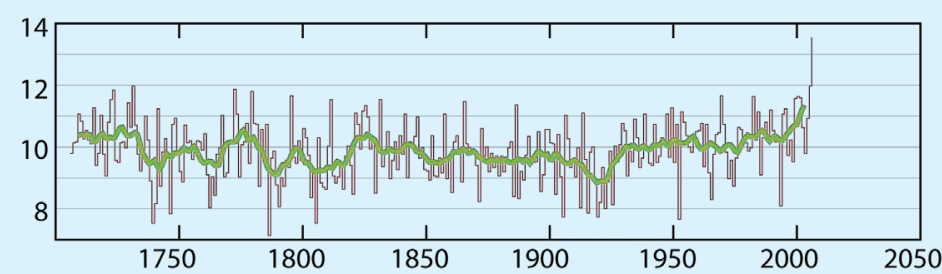

b)

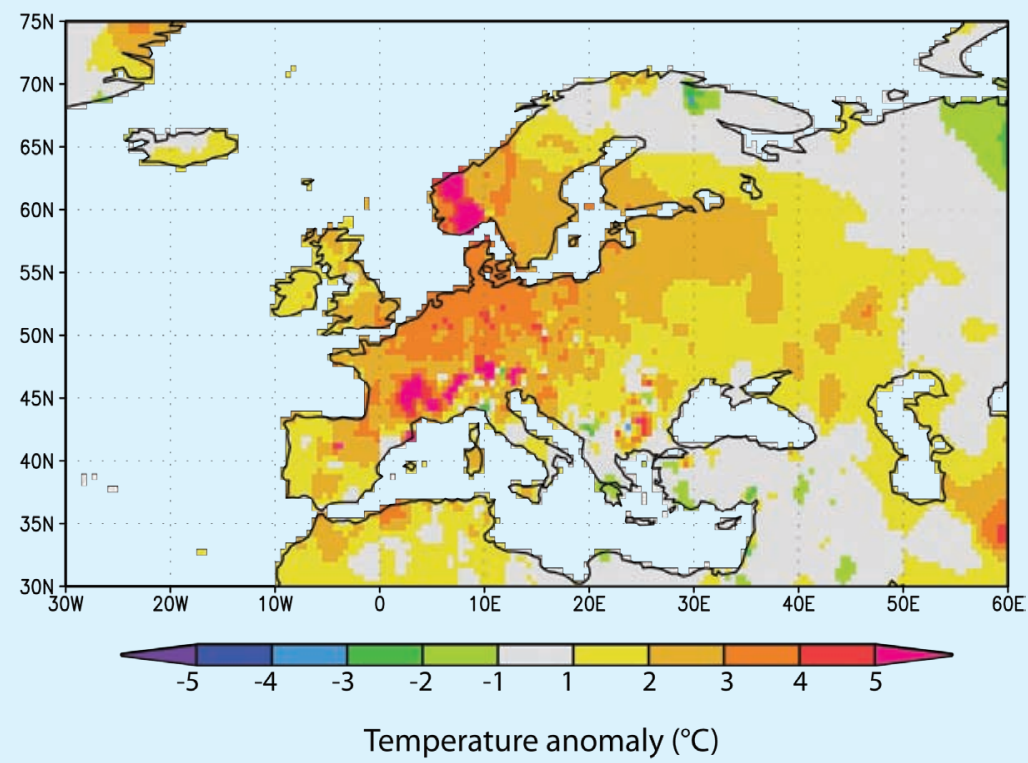

Figure 1: a) Autumn 2-meter temperatures (red) at De Bilt, the Netherlands with a 10-yr running mean (green) 1706-2006 (van Engelen and Nellestijn, 1996). b) The temperature anomaly $\left({ }^{\circ} \mathrm{C}\right)$ (relative to 1961-1990) of Sep-Nov 2006 in the GHCN/CAMS dataset (Fan and van den Dool, 2007).

\section{Global warming}

The effect of global warming on monthly mean local temperature can be described well by a linear relationship:

$$
\mathrm{T}^{\prime}(\mathrm{t})=A \mathrm{~T}_{\text {global }}^{\prime}(\mathrm{t})+\varepsilon(\mathrm{t})
$$

where $A$ indicates how much faster (or slower) the local temperature trend is than the trend in global mean temperature anomalies $\mathrm{T}_{\text {global }}^{\prime}(\mathrm{t})$. The remainder $\varepsilon(\mathrm{t})$ represents the weather noise. In practice, $\mathrm{T}_{\text {global }}^{\prime}(\mathrm{t})$ is smoothed to remove the influences of El Niño and La Niña.

For De Bilt, the factor $A$ is $1.7 \pm 0.4$ in autumn over 1901-2005 (before 1901 both the observations at De Bilt and the global mean temperature have much larger uncertainties). Subtracting the trend $\mathrm{AT}_{\text {global }}^{\prime}(\mathrm{t})$ from the observed temperature we obtain the random fluctuations due to the weather, $\varepsilon(t)$. These are plotted in Figure $2 \mathrm{a}$ as red crosses. The horizontal scale is chosen in such a way that a normal distribution tends to a straight line. The normal distribution that has been fitted to the data is indicated by the central green line in Figure 2a. The upper and lower green lines denote the $95 \%$ confidence interval of the return times derived from the fit. Extrapolation is always a risky exercise and should not be performed without an estimate of the error margins.

The temperature of autumn 2006 above the trend is depicted in Figure $2 \mathrm{a}$ by the horizontal purple line. Even after subtracting the trend, it still is the warmest autumn since 1901, with an anomaly of $2.6 \mathrm{~K}$ above the trend, and a best estimate of the return time of 650 years (the intersection of the central green and purple lines). The $95 \%$ confidence interval is 125 to 10,000 years in De Bilt.

A map of the return times for Europe is shown in Figure $2 b$. Over a large part of Europe, the weather was much warmer than expected from the trend. Estimates of the return times of the weather are longer than 200 years over most of the area where the anomaly was largest, reaching 2000 years in northern Germany and Denmark.

\section{Climate model simulations}

Observed 2006 autumn temperatures greatly exceed the range observed so far, even after accounting for the rise in temperature due to global warming. Do current climate models predict that this type 

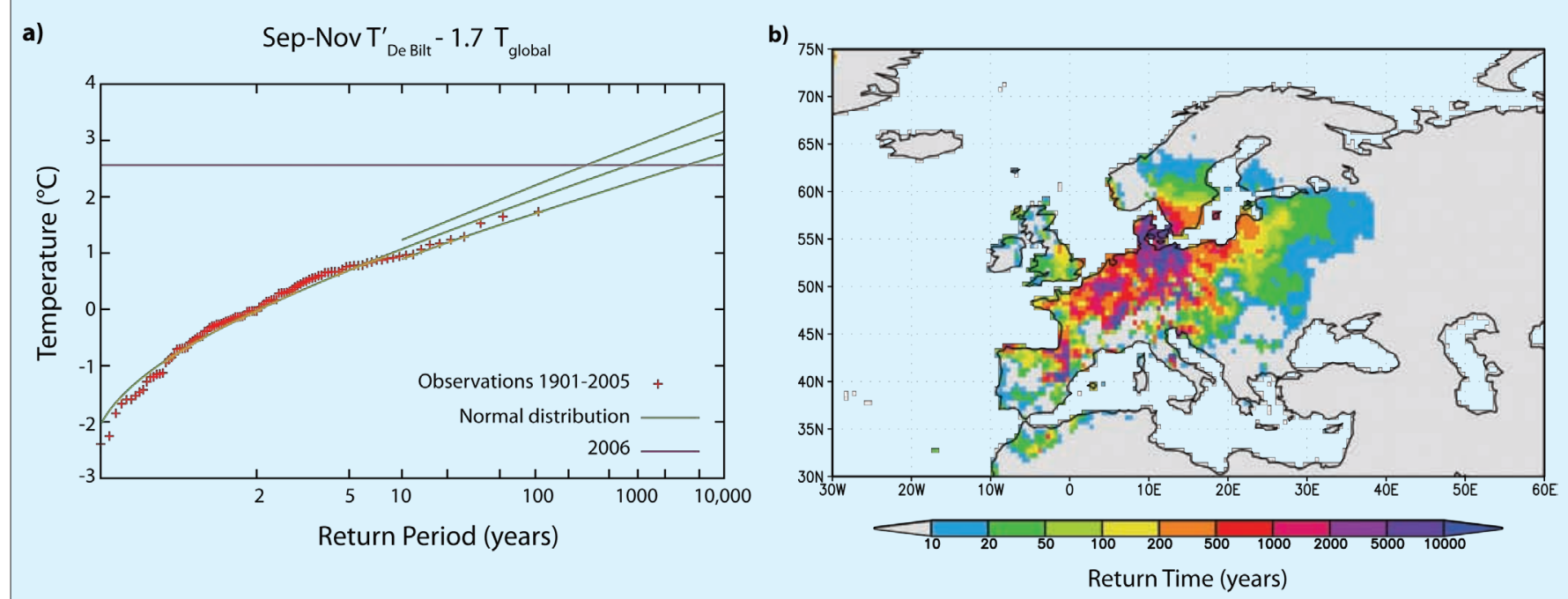

Figure 2: a) Probability distribution of homogenized De Bilt temperatures 1901-2005 (Brandsma et al., 2003) with the linear regression against the global mean temperature anomalies (with a 3-yr running mean) subtracted (red). The intersection of the fit to a normal distribution (green) and the value observed in 2006 (purple) gives the return time of autumn 2006 in De Bilt. b) Return time of autumn 2006 in the context of the years 1948-2005 in Europe.

of extreme events will happen more frequently as Europe heats up?

We investigated the changes in the distribution of autumn temperatures using data from the ESSENCE project: 17 runs with a state-of-the-art climate model (ECHAM5/MPI-OM, Jungclaus et al., 2006) over 1950-2100. These use observed concentrations of greenhouse gases and aerosols up to the year 2000 and the A1b scenario afterwards, which reaches twice the pre-industrial $\mathrm{CO}_{2}$ concentrations in 2100 . This model has the most realistic circulation over Europe of all the models used for the IPCC Fourth Assessment Report (van Ulden and van Oldenborgh, 2006; van den Hurk et al., 2006). Results from this model have been checked against the next four climate models ranked by the realism of the simulated mean circulation over Europe.

There are two ways in which a climate model can simulate lower return times than an extrapolation based on past observations. The first would be that the model indicates that the true, long-term trends are higher than observed so far. The uncertainties in the observations are still large; if, due to natural variability, the trends have been underestimated the fluctuations would not have been as extreme as they appeared. This shows up as a vertical shift in an extreme value graph, like Figure 2a. A second possibility would be that the variability increases, making large fluctuations more likely. This has been shown to occur in summer due to soil moisture effects (e.g., Schär and Jendritzky, 2004; Seneviratne et al., 2006; Fischer et al., 2007). In an extreme value graph, this shows up as steeper lines. a)

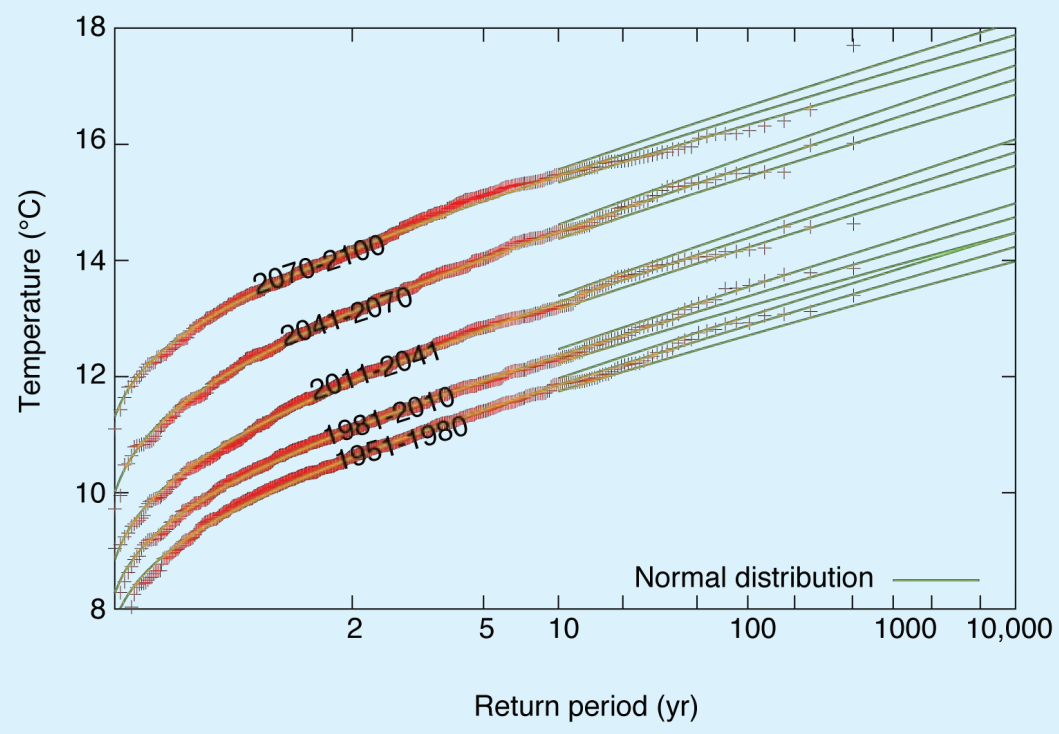

b)

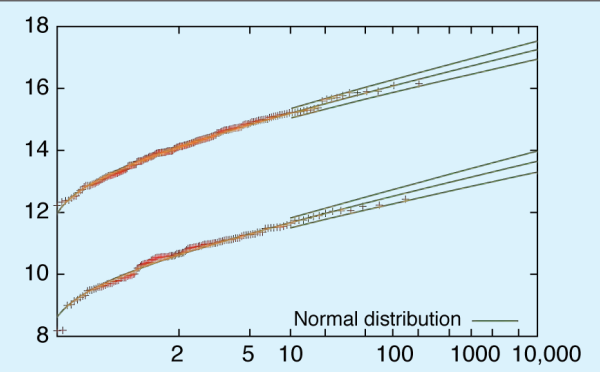

c)

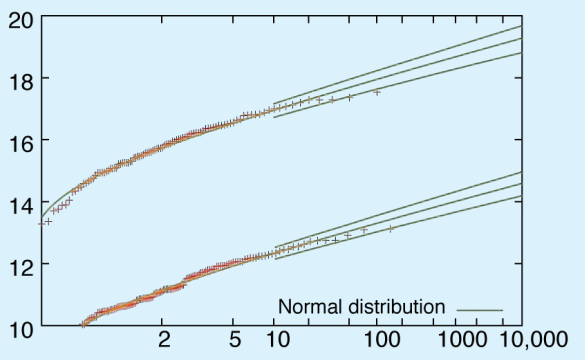

d)

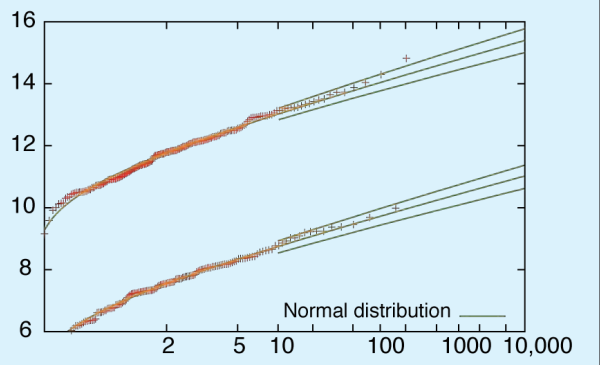

Fiqure 3: a) Extreme autumn temperatures at 52 $\mathrm{N}, 5^{\circ}$ E in 17 ESSENCE runs in 1951-1980, 1981-2010, 2011-2041, 2041-2070 and 2070-2100; in the 20 th and $22^{\text {nd }}$ century runs in the b) GFDL CM2.1, c) UKMO HadGEM1, and d) CCCMA CGCM 3.2 T63 models. Green lines indicate fits to normal distributions (with uncertainties). 
However, the ESSENCE ensemble simulates lower warming trends than the observations in the area where the return times of autumn 2006 are high. The other four models that we considered also show lower than observed trends. If we believe the model trends rather than the observed ones, the return times would be increased to thousands of years.

The 17 ensemble members in ESSENCE enable us to investigate the changes in variability as a function of time. The extreme value distributions of the model surface air temperature at De Bilt have been computed for 30-year intervals, each of which contains 510 years of data. These five curves are shown in Figure 3. There is a clear vertical shift over time: the warming trend. However, there is no indication of an increase in the slopes that would make extremely warm autumn temperatures more likely. This result was confirmed using three other climate models, for which a comparison between the $20^{\text {th }}$ and $22^{\text {nd }}$ centuries could be made. None of these show an increase in the tail of the distribution at the grid point corresponding to De Bilt.
We conclude that current climate models show neither a faster increase in the mean temperature nor an increase in variability that would reduce the return times of autumn 2006.

\section{Conclusions}

The autumn of 2006 was extraordinarily warm in large parts of Europe, with temperatures up to $4^{\circ} \mathrm{C}$ above the 1961-1990 norms. Assuming an unchanging climate, this would correspond to return times of 10,000 years and more.

Global warming has made a warm autumn like the one observed in 2006 much more likely by shifting the temperature distribution to higher values. Taking only this mean warming into account, the best estimate of the return time of the observed temperatures in 2006 is still in excess of 200 years over large parts of Europe.

Current climate models already underestimate the observed mean warming in Europe relative to global warming before 2006. They also do not show an additional increase of the warm tail of the distribution as the climate warms. Either the autumn of 2006 was a very rare event, or these climate models do not give the correct change in temperature distribution as the temperature rises, due to missing feedbacks.

\section{References}

Jungclaus, J.H., Keenlyside, N., Botzet, M., Haak, H., Luo, J.-J., Latif, M., Marotzke, J., Mikolajewicz, U. and Roeckner, E., 2006: Ocean circulation and tropical variability in the coupled model ECHAM5/ MPI-OM, Journal of Climate, 19: 3952-3972, doi:10.1175/ JCLI3827.1.

Luterbacher, J., Liniger, M.A., Menzel, A., Estrella, N., Della-Marta, P.M., Pfister, C., Rutishauser, T. and Xoplaki, E., 2007: The exceptional European warmth of autumn 2006 and winter 2007: Historical context, the underlying dynamics and its phenological impacts, Geophysical Research Letters, 34: L12704, doi:10.1029/2007GL029951.

Schär, C. and Jendritzky, G., 2004: Hot news from summer 2003, Nature, 432: 559-560.

van Oldenborgh, G.J., 2007: How unusual was autumn 2006 in Europe? Climate of the Past, 3: 659-668, www.clim-past. net/3/659/2007/

van Ulden, A.P. and van OIdenborgh, G.J., 2006: Large-scale atmospheric circulation biases and changes in global climate model simulations and their importance for climate change in Central Europe, Atmospheric Chemistry and Physics, 6: 863-881.

For full references please consult:

www.pages-igbp.org/products/newsletter/ref2008_2.html

\title{
Risk prediction of Canadian wildfires
}

\author{
Manfred Mudelsee ${ }^{1,2}$ and Martin P. Girardin ${ }^{3}$ \\ ${ }^{1}$ Climate Risk Analysis, Hannover, Germany; mudelsee@mudelsee.com \\ ${ }^{2}$ Alfred Wegener Institute for Polar and Marine Research, Bremerhaven, Germany; mudelsee@climate-risk-analysis.com \\ ${ }^{3}$ Canadian Forest Service, Natural Resources Canada, Quebec
}

Wildfires in Canada burn on average more than $2 \times 10^{4} \mathrm{~km}^{2}$ of forest per year (Fig. 1) (Stocks et al., 2003), with accompanying economic losses. In years of high fire activity in Canada, the amount of carbon released into the atmosphere by wildfires approaches levels comparable to industrial carbon emissions (Amiro et al., 2001). Predicting the risk (probability) of such extreme events in the regional domain and on mid-term timescales (decades) can serve forest managers, climate and carbon modelers, and the insurance industry. Several requirements have to be met to achieve prediction skill and reliability: data records of sufficient length, climate models able to reproduce observed data properties, and a robust statistical risk estimation method. Results from wildfire records (observed, proxy, and models) analyzed with kernel estimation (a nonparametric smoothing approach), reveal that by the end of the $21^{\text {st }}$ century, wildfire risk for Canada may rise and eventually exceed the high levels observed in the previous two centuries.

\section{Data: Wildfire proxy records}

Records of directly observed wildfire events are sparse and cover too short a time frame for risk analysis of extreme (i.e., rare) events. This study considered only large (> $200 \mathrm{ha}$ ) fires, from the Large Fire Data Base (Stocks et al., 2003) to achieve a

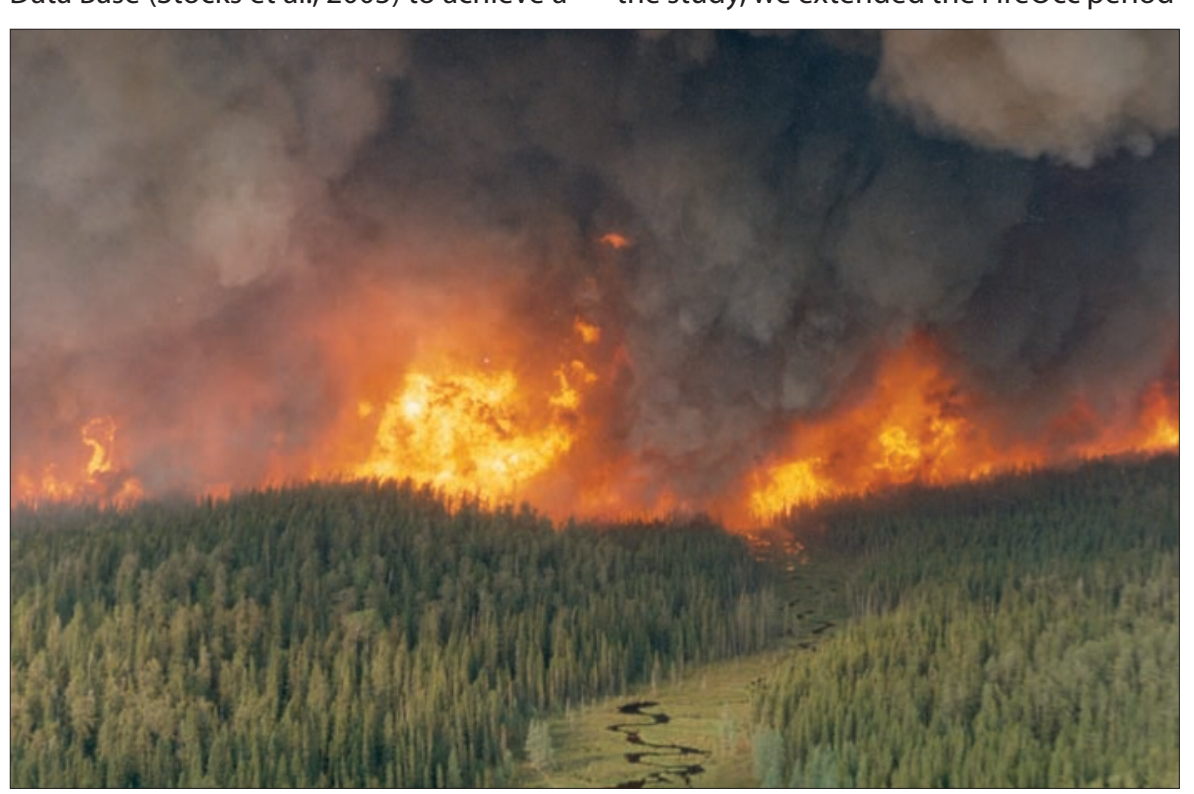

Figure 1: Red Lake forest fire, Ontario (photo by Brian Stocks, Canadian Forest Service). high degree of data homogeneity over the observation period, 1959 to 1998 . These large fires account for $97 \%$ of the total area burnt in Canada. The variable "FireOcc" represents the number of large fires per year. To broaden the temporal coverage of the study, we extended the FireOcc period 